\title{
Expression microarray analysis identifies novel epithelial-derived protein markers in eosinophilic esophagitis
}

Andres Matoso ${ }^{1,2,3}$, Vincent A Mukkada ${ }^{2,3}$, Shaolei Lu ${ }^{1}$, Renee Monahan ${ }^{1}$,
Kelly Cleveland $^{1}$, Lelia Noble ${ }^{1}$, Shamlal Mangray ${ }^{1}$ and Murray B Resnick ${ }^{1}$

${ }^{1}$ Department of Pathology and Laboratory Medicine, Rhode Island Hospital and Alpert Medical School of Brown University, Providence, RI, USA and ${ }^{2}$ Division of Pediatric Gastroenterology, Nutrition and Liver Diseases, Rhode Island Hospital and Alpert Medical School of Brown University, Providence, RI, USA

Gene expression studies in eosinophilic esophagitis support an immune-mediated etiology associated with differential regulation of inflammatory and epithelial-derived genes. We aimed to further characterize epithelial gene expression alterations in eosinophilic esophagitis and to explore the use of immunohistochemistry to identify these alterations. Esophageal biopsies from pediatric patients with eosinophilic esophagitis before and after therapy with topical steroids $(N=7)$ were screened by gene expression microarray and results were validated by RT-PCR. A larger group of eosinophilic esophagitis patients $(N=42)$ was then used to evaluate protein expression by immunohistochemistry compared with reflux patients $(N=15)$ and normal controls $(N=17)$. Microarray and RT-PCR studies identified overexpression of $A L O X 15$ and tumor necrosis factor alphainduced factor 6 (TNFAIP6) and underexpression of filaggrin (FLG), SLURP1 and cysteine-rich secretory protein 3 (CRISP3) in eosinophilic esophagitis. Immunohistochemistry for ALOX15 was positive in $95 \%$ of eosinophilic esophagitis and negative in all controls, all eosinophilic esophagitis after therapy and all reflux biopsies $(P<0.001)$. TNFAIP6 was positive in $88 \%$ of eosinophilic esophagitis samples versus $47 \%$ of controls, $29 \%$ of eosinophilic esophagitis after therapy and $40 \%$ of reflux samples $(P=0.002)$. Overexpression of both ALOX15 and TNFAIP6 directly correlated with the degree of eosinophilic infiltration. FLG was positive in $88 \%$ of controls and $100 \%$ of reflux biopsies, but negative in all eosinophilic esophagitis samples, and its expression was regained in $86 \%$ of eosinophilic esophagitis after therapy patients $(P<0.001)$. SLURP1 expression was positive in all controls and reflux samples, but only positive in $5 \%$ of eosinophilic esophagitis and was re-expressed to $100 \%$ positivity in eosinophilic esophagitis after therapy patients $(P<0.001)$. The majority of controls $(89 \%)$ and reflux biopsies $(100 \%)$ were positive for CRISP3 while eosinophilic esophagitis before therapy were positive in $14 \%$ of samples $(P<0.001)$ with partial recovery after treatment $(43 \%, P=0.105)$. This study identified five epithelial-derived markers differentially expressed in eosinophilic esophagitis easily detectable by immunohistochemistry with potential diagnostic utility.

Modern Pathology (2013) 26, 665-676; doi:10.1038/modpathol.2013.41; published online 15 March 2013

Keywords: ALOX15; CRISP3; eosinophilic esophagitis; FLG; immunohistochemistry; SLURP1; TNFAIP6

Eosinophilic esophagitis was first recognized as a separate entity responsive to anti-allergic treatment and elemental diets in the mid-1990s. ${ }^{1}$ It is a significant source of morbidity in both children and

Correspondence: Dr MB Resnick, MD, PhD, Department of Pathology and Laboratory Medicine, Rhode Island Hospital and Alpert Medical School of Brown University, 593 Eddy Street, Providence, RI 02903, USA.

E-mail: mresnick@lifespan.org

${ }^{3}$ These authors contributed equally to this work.

Received 6 November 2012; revised 15 January 2013; accepted 16

January 2013; published online 15 March 2013 adults. $^{2,3}$ Currently, the clinical diagnosis of the disease is based on the correlation of clinical and histological findings. The evaluation of hematoxylin and eosin-stained tissue sections relies heavily on morphologic features that overlap with those of gastroesophageal reflux disease. ${ }^{4}$ The clinical signs and symptoms are nonspecific and also overlap significantly with those of reflux, ${ }^{5}$ and thus differentiating between the two diseases is one of the primary challenges in caring for patients with eosinophilic esophagitis.

Although the pathogenesis of eosinophilic esophagitis remains unclear, a supporting role for allergy 
seems likely given symptomatic improvement with food allergen elimination and the correlation noted between seasonal variations in pollens and eosinophilic esophagitis diagnosis. ${ }^{6}$ A number of studies of the mucosal transcriptome associated with eosinophilic esophagitis, demonstrate dysregulated genes involving all cellular players including eosinophils, lymphocytes, mast cells, esophageal epithelial cells and subepithelial myofibroblasts. ${ }^{7-9}$ These studies show an important role of mediators of a Th2 inflammatory response, including IL-4, IL-5, IL-13 and eotaxins. ${ }^{7,8,10-12}$ Further studies have investigated gene expression alterations directly associated with IL-13 stimulation of esophageal epithelial cell cultures. These have shown upregulation of inflammation-related genes including tumor necrosis factor alpha-induced factor 6 (TNFAIP6) and downregulation of the innate immunity associated cysteine-rich secretory protein 3 (CRISP3) and epidermal differentiation factors including filaggrin $(F L G){ }^{8}$ These studies suggest a pathogenic mechanism in which upregulation of inflammatory mediators leads to downregulation of epithelial differentiation factors and subsequent weakening of the epithelial barrier properties. We aimed to further characterize variation in epithelial gene expression of eosinophilic esophagitis biopsies to identify a subset of markers that would be consistently differentially expressed in eosinophilic esophagitis and that their protein product could be detected by immunohistochemistry. We performed an initial gene expression microarray screening using paired samples of pediatric patients with eosinophilic esophagitis before and after successful treatment. We then proceeded to validate microarray results by RT-PCR. Finally, we investigated the protein expression by immunohistochemistry comparing biopsies from a larger group of pediatric eosinophilic esophagitis patients to biopsies of patients with reflux and to normal controls.

\section{Materials and methods}

\section{Patients and Tissue Samples}

Archival esophageal biopsies were obtained from the Pathology Department of Rhode Island Hospital (Providence, RI, USA). The study was performed according to a protocol approved by the institutional review board of Lifespan/Rhode Island Hospital. The cohort included pediatric patients (ages 0-18) with the diagnosis of eosinophilic esophagitis for whom biopsies where available before and after treatment $(N=7)$, normal controls $(N=17)$ and eosinophilic esophagitis patients for whom only the initial biopsy was available $(N=35)$. In addition, a cohort of pediatric patients with reflux esophagitis was included for comparison $(N=15)$. Diagnosis of eosinophilic esophagitis was made as defined by the
2011 consensus guidelines. ${ }^{13}$ Specifically, patients were required to have symptoms of esophageal dysfunction, one or more esophageal biopsies with a minimum of 15 eosinophils per high-power field and other causes of esophageal eosinophilia excluded. Selection criteria of reflux esophagitis included clinical presentation and histopathology consistent with reflux in patients with good symptomatic response to acid suppression. All biopsies had previously been collected for clinical purposes. Sections $(4 \mu \mathrm{m})$ were cut from each block and stained with hematoxylin and eosin. The slides were reviewed by two pathologists (AM and MBR) to confirm the histologic diagnosis. Basal cell hyperplasia was defined as negative $(<25 \%$ of the thickness) mild (26-50\%), moderate (50-75\%) and severe $(75-100 \%)$. Elongated papillae was defined as papillae $>50 \%$ of the epithelial thickness. The clinical data were reviewed by a pediatric gastroenterologist (VAM) to ensure that these patients fit the diagnostic selection criteria.

\section{RNA Extraction}

Tissue sections $(10 \mu \mathrm{m})$ were cut and mounted onto plain glass slides and subjected to manual macrodissection or laser-capture microdissection to isolate the epithelial cell population from the underlying stroma. Total RNA was extracted using the Recover All Total Nucleic Acid Extraction Kit for formalinfixed paraffin-embedded tissues (Ambion, Grand Island, NY, USA), including DNAse incubation to remove genomic DNA from the RNA sample. RNA was further purified and concentrated using the RNEasy Minelute Cleanup Kit (Qiagen, Valencia, CA, USA), and then evaluated by the Agilent Bioanalyzer using an RNA 6000 Nano or Pico LabChip (Agilent Technologies, Santa Clara, CA, USA) as described previously. ${ }^{14}$

\section{Amplification of Total RNA for mRNA Expression Analysis by Affymetrix GeneST Array}

Fifty nanograms of total RNA was amplified and transcribed into cDNA using the Ovation FFPE WTA system (Nugen Technologies, San Carlos, CA, USA). In all, $5-10 \mu \mathrm{g}$ of amplified SPIA cDNA from the amplification above was fragmented and labeled for Affymetrix array analysis using the Encore Biotin Module (Nugen Technologies). Array hybridization and analysis was performed by the Genomics Core Facility at the Center for Genomics and Proteomics (Brown University, Providence, RI, USA).

\section{Immunohistochemistry}

Five-micron sections were deparaffinized, processed through a graded series of alcohols and rehydrated in distilled water per standard protocols. 
Heat-induced antigen retrieval was performed in citrate buffer ( $10 \mathrm{mmol} / \mathrm{l}$ concentration, $\mathrm{pH}$ 6) for $10 \mathrm{~min}$. Tissue sections were incubated with peroxidase block (Dako, Carpinteria, CA, USA) or dry milk-based solution for $5 \mathrm{~min}$ to minimize background reactivity. The Dako Envision Plus Kit (Dako North America, Carpinteria, CA, USA) was used to perform the polymer-horseradish peroxidase-based IHC using the following antibodies: SLURP1 (Clone 569317; R\&D Systems, Minneapolis, MN, USA; 1:100 dilution), CRISP3 (clone 295203, R\&D Systems; 1:100 dilution), FLG (SPM181, Abcam, Cambridge, MA, USA; 1:25 dilution), ALOX15 (11-K, Santa Cruz Biotechnology, Santa Cruz, CA, USA; 1:100 dilution) and TNFAIP6 (FL-277, Santa Cruz Biotechnology; 1:200 dilution). Sections of stomach, small intestine and colon were used as positive controls for ALOX15 and TNFAIP6 in which inflammatory cells were positive. For FLG, SLURP1 and CRISP3, sections of normal esophagus were used as positive control. Negative controls where achieved by replacing the primary antibody by normal serum. Results were scored using a semiquantitative system for extent and intensity of staining. For extent, points were assigned as follows: $0=$ negative; $1=$ up to $10 \%$ positive cells; $2=10-$ $50 \%$ positive cells; $3=>50 \%$ positive cells. For intensity, points were assigned as follows: $0=$ negative; $1=$ weakly positive; $2=$ moderately positive; $3=$ intensely positive. A total score of 3 or higher was considered positive and 2 or lower was considered negative. Based on the pattern of staining for each one of the markers, ALOX15 and TNFAIP6 were scored in the full epithelial thickness; FLG and SLURP1 were scored in the mid and superficial levels of the epithelium; CRISP3 was scored in the basal cell layer peripapillary cells and superficial squamous cells. Owing to the discontinuous nature of eosinophilic esophagitis, 'patchy' lesions were graded in areas of histologic changes consistent with eosinophilic esophagitis. AM and MBR independently scored each section. Concordance was high and discrepant cases were reviewed to reach consensus.

\section{Quantitative RT-PCR}

Primers were designed using the PrimerQuest tool and synthesized by Integrated DNA Technologies (Coralville, IA, USA). Primer sequences used are as follows: ALOX15 forward: 5'-TGGAAGGACGGGTT AATTCTGA-3 ${ }^{\prime}$, reverse: $5^{\prime}$-GCGAAACCTCAAAGTCA ACTCT-3'; TNFAIP6 forward: 5'-ATTGCTACAACCCA CACGCAAAGG- ${ }^{\prime}$, reverse: $5^{\prime}$-TCGTACTCATTTGGG AAGCCTGGA-3'; FLG forward: $5^{\prime}$-TGGGTCTGCTTC CAGAAACCATCT- ${ }^{\prime}$, reverse: 5'-TGTGTGACGAGTG CCTGATTGTCT-3', SLURP1 forward: 5'-TCATCACTT CTGAGCACGGAGCAA- $3^{\prime}$, reverse: 5'-TGTGTGACG AGTGCCTGATTGTCT-3'; CRISP3 forward: 5'-TACC CTCCACTCAAGGAGGTAGAACT-3' ${ }^{\prime}$, reverse: $5^{\prime}$-CCC
TTTCCATACTCCACTCTTTGG-3'. RT-PCR was performed on an Agilent MX3005p qPCR instrument using Brilliant III SYBR Green Master Mix reagents (Agilent Technologies) according to the manufacturer protocol. Human $\beta$-actin was used to normalize qPCR results. Results are expressed in fold change calculated using the ddCt method and expressed as mean \pm s.e.m.

\section{Statistical Analysis}

Statistical analysis was performed using the GraphPad Prism Software. P-values were calculated using the Mann-Whitney test for qPCR results and Fisher's exact test and $T$-test for immunohistochemistry results. Differences were considered significant at a $P$-value of equal or $<0.05$ and expressed as mean \pm s.e.m.

\section{Results}

\section{Study Population}

The clinical and pathologic characteristics of all patients are summarized in Table 1. All patients underwent upper endoscopy and biopsies were taken from the proximal and distal esophagus. Of the seven patients with biopsies before and after therapy, five tested positive for food allergies based on skin-prick and serum-specific IgE testing. All of these patients responded completely with histologic remission following standard therapy with either topical fluticasone or budesonide.

All of the pre-treatment biopsies revealed classical features of eosinophilic esophagitis including intraepithelial eosinophils $>15$ per high-power view (ranging from 35 to over 100 per high-power view), superficial eosinophilic microabscesses, basal layer hyperplasia and subepithelial fibrosis. The post-treatment biopsy material consisted of normal appearing squamous mucosa with only rare intraepithelial eosinophils numbering $<2$ per high-power view (Figure 1).

The reflux biopsies had histopathologic features consistent with reflux including basal cell hyperplasia, papillary elongation and up to 14 eosinophils per high-power view. All patients with the diagnosis of reflux responded successfully to therapy with acid suppression with remission of symptoms.

The normal control group was composed of pediatric patients who underwent endoscopy because of gastrointestinal symptoms whose biopsies had normal esophageal mucosa.

\section{Identification of Eosinophilic Esophagitis mRNA Transcripts}

A group of seven patients with biopsies before and after successful therapy with corticosteroids was subjected to gene expression microarray analysis. In order to minimize biological variability, we used 
Table 1 Clinical and pathologic characteristics of patients

\begin{tabular}{|c|c|c|c|c|}
\hline & $\begin{array}{c}\text { Eosinophilic } \\
\text { esophagitis } \\
(\mathrm{N}=42)\end{array}$ & $\begin{array}{l}\text { Eosinophilic esophagitis } \\
\text { after treatment } \\
(\mathrm{N}=7)\end{array}$ & $\begin{array}{c}\text { Reflux } \\
(\mathrm{N}=15)\end{array}$ & $\begin{array}{l}\text { Normal } \\
(\mathrm{N}=17)\end{array}$ \\
\hline Age (mean \pm s.d.) & $10.01 \pm 5.17$ & $7.0 \pm 5.03$ & $10.13 \pm 5.02$ & $10.52 \pm 4.59$ \\
\hline Sex (M:F) & $32: 10$ & $5: 2$ & $7: 8$ & $10: 7$ \\
\hline \multicolumn{5}{|l|}{ Symptoms } \\
\hline Abdominal pain (\%) & $21(50)$ & $2(29)$ & $11(73)$ & $11(64)$ \\
\hline Vomiting (\%) & $18(43)$ & $0(0)$ & $12(80)$ & $3(18)$ \\
\hline Dysphagia (\%) & $28(66)$ & $1(14)$ & $3(20)$ & $1(6)$ \\
\hline Food impaction (\%) & $12(29)$ & $0(0)$ & $0(0)$ & $0(0)$ \\
\hline Heartburn (\%) & $14(33)$ & $0(0)$ & $4(27)$ & $3(18)$ \\
\hline Failure to thrive (\%) & $8(19)$ & $1(14)$ & $2(13)$ & $1(6)$ \\
\hline \multicolumn{5}{|l|}{ Endoscopy } \\
\hline Normal (\%) & $1(2)$ & $1(14)$ & $8(53)$ & $14(82)$ \\
\hline Erythema (\%) & $24(57)$ & $2(29)$ & $4(27)$ & $0(0)$ \\
\hline Rings (\%) & $3(7)$ & $1(14)$ & $0(0)$ & $1(6)$ \\
\hline Ridging (\%) & $22(52)$ & $1(14)$ & $1(6)$ & $1(6)$ \\
\hline Furrows & $29(69)$ & $4(57)$ & $1(6)$ & $0(0)$ \\
\hline White plaques & $29(69)$ & $2(29)$ & $0(0)$ & $0(0)$ \\
\hline Erosion & $5(12)$ & $0(0)$ & $2(13)$ & $0(0)$ \\
\hline \multicolumn{5}{|l|}{ Allergies } \\
\hline Food allergy (\%) & $22(52)$ & $6(85)$ & $1(6)$ & $1(6)$ \\
\hline Asthma (\%) & $14(33)$ & $2(29)$ & $0(0)$ & $1(6)$ \\
\hline Rhinitis or dermatitis (\%) & $16(38)$ & $2(29)$ & $1(6)$ & $1(6)$ \\
\hline \multicolumn{5}{|l|}{ Histopathology } \\
\hline Eosinophils/HPF (mean \pm s.d.) & $55.38 \pm 24.95$ & $0.57 \pm 0.97$ & $6.6 \pm 2.79$ & $0 \pm 0$ \\
\hline Basal cell hyperplasia & $36(86)$ & $0(0)$ & $12(80)$ & $0(0)$ \\
\hline Mild $(26-50 \%)$ & $6(15)$ & $0(0)$ & $11(73)$ & $0(0)$ \\
\hline Moderate (51-75\%) & $13(30)$ & $0(0)$ & $1(6)$ & $0(0)$ \\
\hline Severe $(75-100 \%)$ & $17(40)$ & $0(0)$ & $0(0)$ & $0(0)$ \\
\hline Papillary elongation & $32(76)$ & $2(29)$ & $8(53)$ & $0(0)$ \\
\hline Microabscesses & $7(17)$ & $0(0)$ & $0(0)$ & $0(0)$ \\
\hline Degranulation & $36(85)$ & $0(0)$ & $2(13)$ & $0(0)$ \\
\hline
\end{tabular}

paired samples from the same individual before and after treatment. Of the 29095 transcripts represented on these microarrays, 914 transcripts were differentially expressed $(P<0.01)$. By using the gene ontology analysis tool DAVID (Database for Annotation, Visualization and Integrated Discovery), a selection of epithelial-derived genes most differentially expressed ( $>3$-fold change) identified 31 transcripts including 12 upregulated and 19 downregulated genes (Table 2).

The majority of upregulated genes are related to inflammation including the differentially expressed TNFAIP 6 and ALOX15 that were increased 39.24 and 10.31-fold in eosinophilic esophagitis before treatment compared with eosinophilic esophagitis after treatment biopsies. Within the set of downregulated genes, those most differentially expressed included several involved with epithelial integrity and innate immunity including CRISP3 (-44.81fold change), SLURP1 (-8.131-fold change) and FLG ( - 5.571-fold change).

\section{Validation of Individual mRNA Expression by Quantitative RT-PCR}

Selection of target genes to be validated by RT-PCR included those that showed the greatest degree of differential expression and for which there was a commercially available antibody for immunohistochemistry and performed satisfactorily on paraffinembedded tissues in preliminary studies. Validation of microarray results was performed by using four paired biopsies from eosinophilic esophagitis before and after treatment. Correlation between microarray and RT-PCR results was defined as change in expression in the same direction with a magnitude of at least 2.0-fold and a $P$-value of $<0.05$. Although the majority of genes selected by microarray analysis showed the same direction of change by RT-PCR, targets that were consistently differentially expressed and that met the validation criteria mentioned above were limited to five genes. Among upregulated genes, validation was successful for ALOX15 and TNFAIP6. Compared with eosinophilic esophagitis after treatment samples, expression of $A L O X 15$ was $7.01 \pm 3.6$-fold higher in eosinophilic esophagitis before treatment samples $(P=0.02)$. Similarly, expression of TNFAIP6 was $6.17 \pm 2.51$ fold higher in eosinophilic esophagitis before treatment compared with after treatment samples $(P=0.04$; Figure 2). Among downregulated genes, RT-PCR results that met the correlation criteria included FLG, SLURP1 and CRISP3. Expression of these initially downregulated genes were 
a
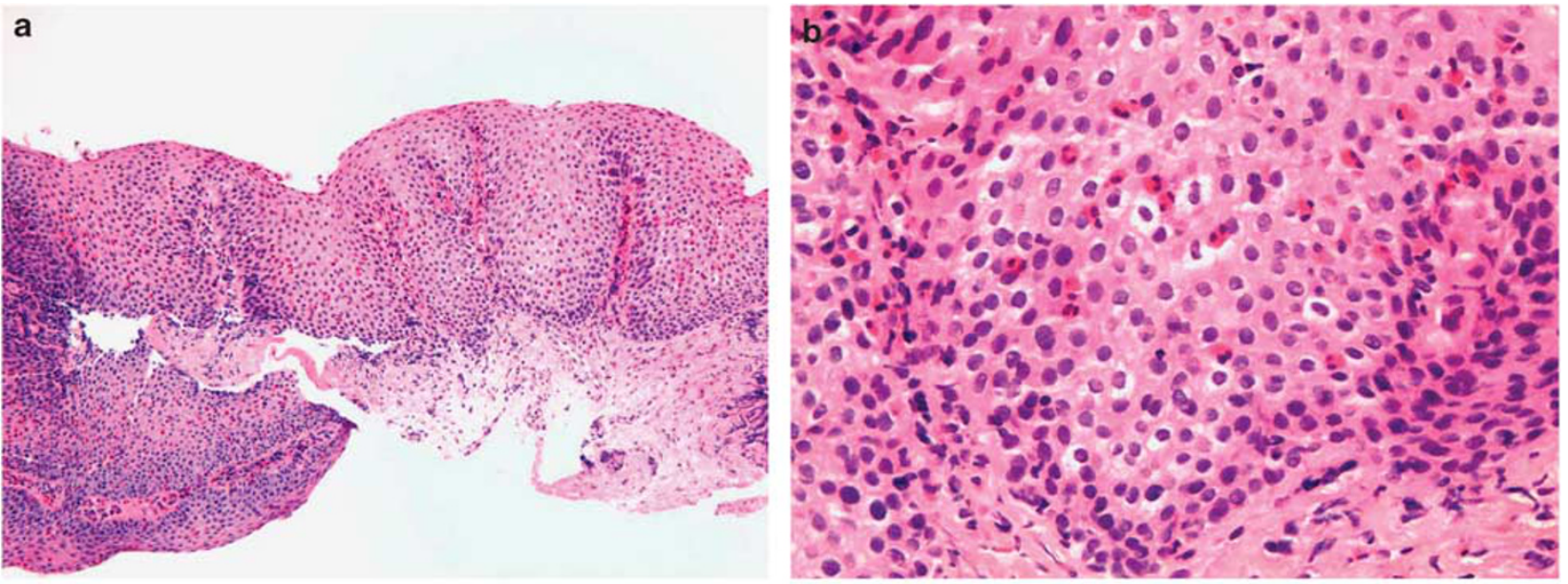

c
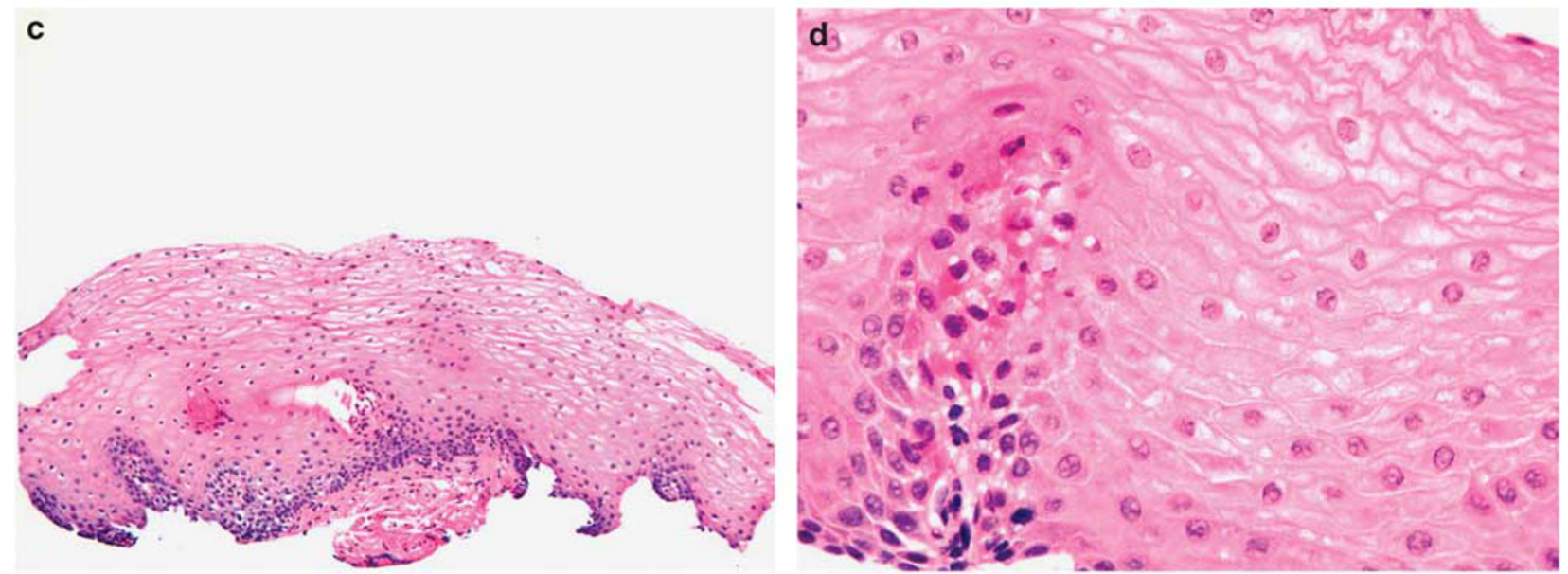

Figure 1 Histopathologic features of eosinophilic esophagitis biopsies before and after successful treatment with corticosteroids. (a, b) Biopsies of eosinophilic esophagitis before therapy. (a) Low-power view shows basal cell hyperplasia, papillary elongation and numerous intraepithelial eosinophils. (b) High-power view shows epithelial cells with reactive nuclear changes and marked eosinophilic infiltration. (c, d) Biopsies of eosinophilic esophagitis after therapy. (c) Low-power view shows normalized mucosa with normal epithelial maturation and resting basal cell layer. (d) High-power view highlights absence of intraepithelial eosinophils and epithelial cells with small pyknotic nuclei and normal maturation of cytoplasms.

upregulated after therapy by a fold change of $5.37 \pm 1.63$ for $F L G(P=0.01), 2.42 \pm 0.42$ for SLURP1 $(P=0.02)$ and $40.12 \pm 7.00$ for CRISP3 $(P=0.02$; Figure 2).

\section{Immunohistochemistry}

Next, we tested protein expression of ALOX15, TNFAIP6, FLG, SLURP1 and CRISP3 by immunohistochemistry. For this portion of the study, a larger group of biopsies from pediatric eosinophilic esophagitis patients $(N=42$; including the seven eosinophilic esophagitis before treatment samples used for mRNA studies) was compared with biopsies from patients with eosinophilic esophagitis after treatment, biopsies from pediatric patients with the diagnosis of reflux $(N=15)$, and to normal pediatric esophageal biopsies $(N=17)$. The immunohistochemistry results are summarized in Table 3.

Consistent with the mRNA studies presented above, eosinophilic esophagitis samples demonstrated overexpression of ALOX15 and TNFAIP6. Expression of ALOX15 was present diffusely throughout the cytoplasm of squamous cells and in inflammatory cells (including eosinophils) of $95 \%$ of eosinophilic esophagitis biopsies. Staining was diffusely and strongly positive in the majority of biopsies, especially in cases with marked basal cell hyperplasia. ALOX15 was not seen in any of the eosinophilic esophagitis after treatment biopsies or in the reflux $(P<0.001)$ or normal controls $(P<0.001)$. Expression of TNFAIP6 was present in the cytoplasm of squamous cells in the majority of patients with eosinophilic esophagitis (88\%) and was expressed in some of eosinophilic esophagitis after treatment biopsies $(29 \%, P=0.002)$, reflux $(40 \%, P<0.001)$ and normal controls $(47 \%$, $P=0.002$; Table 3 and Figure 3).

Staining for FLG and SLURP1 was present in the mid and superficial layers of the squamous epithelium in the majority of normal controls $(88 \%$ and $100 \%$, respectively) and in all reflux biopsies. In 
Table 2 Epithelial genes differentially expressed by microarray analysis

\begin{tabular}{|c|c|c|c|}
\hline Symbol & Entrez gene name & Location & Fold change \\
\hline \multicolumn{4}{|l|}{ Upregulated in EoE } \\
\hline TNFAIP6 & Tumor necrosis factor, alpha-induced protein 6 & Cytoplasm & 39.24 \\
\hline$A L O X 15$ & Arachidonate 15-lipoxygenase & Cytoplasm & 10.31 \\
\hline CCL26 & Chemokine (C-C motif) ligand 26 & Extracellular space & 8.415 \\
\hline HPGDS & Hematopoietic prostaglandin D synthase & Cytoplasm & 5.871 \\
\hline $\begin{array}{l}P K P 2 \text { (includes } \\
E G: 287925)\end{array}$ & Plakophilin 2 & Plasma membrane & 5.342 \\
\hline FOXE1 & Forkhead box E1 (thyroid transcription factor 2) & Nucleus & 4.438 \\
\hline SYNPO & Synaptopodin & Cytoplasm & 4.415 \\
\hline CXCR4 & Chemokine (C-X-C motif) receptor 4 & Plasma membrane & 4.092 \\
\hline $\mathrm{CDH} 3$ & Cadherin 3 , type 1 , P-cadherin (placental) & Plasma membrane & 4.065 \\
\hline KITLG & KIT ligand & Extracellular space & 3.939 \\
\hline$C L U$ & Clusterin & Cytoplasm & 3.431 \\
\hline TNFSF13 & Tumor necrosis factor (ligand) superfamily, member 13 & Extracellular space & 3.116 \\
\hline \multicolumn{4}{|l|}{ Downregulated in EoE } \\
\hline CRISP3 & Cysteine-rich secretory protein 3 & Cytoplasm & -44.81 \\
\hline SPINK7 & Serine peptidase inhibitor, Kazal type 7 (putative) & Cytoplasm & -37.81 \\
\hline EPB41L3 & Erythrocyte membrane protein band 4.1-like 3 & Plasma membrane & -14.556 \\
\hline$E P G N$ & Epithelial mitogen homolog & Cytoplasm & -11.51 \\
\hline$A L O X 12$ & Arachidonate 12-lipoxygenase & Cytoplasm & -8.641 \\
\hline SLURP1 & Secreted LY6/PLAUR domain containing 1 & Cytoplasm & -8.131 \\
\hline$I L 12 A$ & $\begin{array}{l}\text { Interleukin } 12 \mathrm{~A} \text { (natural killer cell stimulatory factor } 1 \text {, cytotoxic } \\
\text { lymphocyte maturation factor } 1, \mathrm{p} 35 \text { ) }\end{array}$ & Extracellular space & -6.249 \\
\hline SPRR $2 B$ & Small proline-rich protein $2 \mathrm{~B}$ & Cytoplasm & -6.211 \\
\hline$A I F 1 L$ & Allograft inflammatory factor 1-like & Plasma membrane & -6.087 \\
\hline FLG & Filaggrin & Cytoplasm & -5.571 \\
\hline $\begin{array}{l}\text { CST6 (includes } \\
\text { EG:1474) }\end{array}$ & Cystatin E/M & Extracellular space & -4.254 \\
\hline CXCR2 & Chemokine (C-X-C motif) receptor 2 & Plasma membrane & -4.123 \\
\hline$E M P 1$ & Epithelial membrane protein 1 & Plasma membrane & -4.01 \\
\hline CGNL1 & Cingulin-like 1 & Plasma membrane & -3.948 \\
\hline DHRS9 & Dehydrogenase/reductase (SDR family) member 9 & Cytoplasm & -3.882 \\
\hline RHCG & Rh family, C glycoprotein & Plasma membrane & -3.7 \\
\hline HIF1A & $\begin{array}{l}\text { Hypoxia-inducible factor 1, alpha subunit (basic helix-loop-helix } \\
\text { transcription factor) }\end{array}$ & Nucleus & -3.449 \\
\hline$S C N N 1 B$ & Sodium channel, nonvoltage-gated 1 , beta & Plasma membrane & -3.284 \\
\hline SPRR2A (includes others) & Small proline-rich protein $2 \mathrm{~A}$ & Cytoplasm & -3.021 \\
\hline
\end{tabular}

eosinophilic esophagitis biopsies, expression of both FLG and SLURP1 was significantly downregulated ( $0 \%$ and $5 \%$, respectively). Notably, none of the reflux biopsies exhibited loss of expression of either FLG or SLURP1. Following successful therapy, all biopsies regained expression of SLURP1 $(P<0.001)$ and the majority of eosinophilic esophagitis after treatment biopsies $(86 \%)$ expressed moderate-to-strong stain for FLG $(P<0.001)$. Staining for CRISP3 was seen in the majority of normal controls (82\%) and all reflux biopsies in two different distributions patterns within the squamous epithelium (cytoplasm of basal cells and in the mid to superficial layers squamous cells). Eosinophilic esophagitis before treatment biopsies showed decreased CRISP3 expression (14\%) with partial recovery of expression after therapy $(43 \%, P=0.105$; Table 3 and Figure 4$)$.

Based on these immunohistochemistry results, the highest sensitivity and specificity as diagnostic markers were achieved by overexpression of ALOX15 (95\% and 100\%, respectively), and by loss of expression of FLG (100\% and 92\%, respectively) and SLURP1 (95\% and 96\%, respectively).
As positive immunohistochemical markers are usually preferred clinically, we decided to investigate whether overexpression of ALOX15 and TNFAIP6 correlated with the degree of intraepithelial eosinophilia, by comparing the extent and intensity of immunohistochemical staining in areas of different degrees of eosinophilic infiltration. Following the scoring system described in Materials and methods section, a randomly selected group of 15 cases of eosinophilic esophagitis was scored in areas with no eosinophils, 1 to 15 eosinophils per high-power view and $>15$ eosinophils per highpower view. The average score for ALOX15 expression was $0.76 \pm 0.32$ in areas with no eosinophils compared with $4.29 \pm 0.26$ in areas with 1 to 15 eosinophils, and to $5.35 \pm 0.20$ in areas with $>15$ eosinophils per high-power field $(P<0.001)$. Similarly, expression of TNFAIP6 averaged $0.77 \pm 0.44$ in areas with no eosinophils, $2.94 \pm 0.31$ in areas with 1 to 15 eosinophils per high-power view, and $3.55 \pm 0.42$ in areas with $>15$ per high-power view $(P=0.01$; Figure 5$)$. These results indicate that expression of ALOX15 and TNFAIP6 directly correlates with the degree of eosinophilic infiltration. 

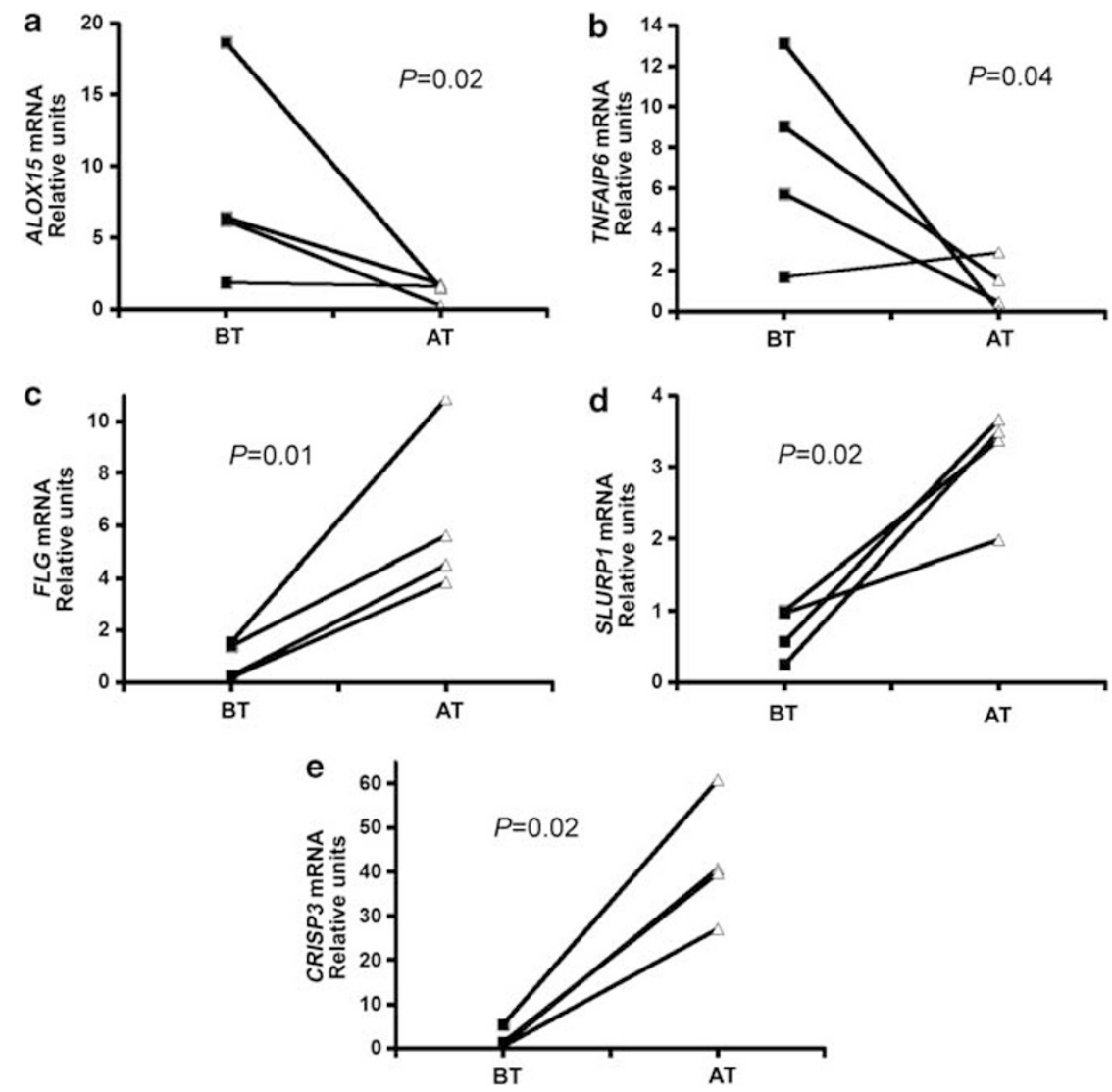

Figure 2 Real-time reverse transcription-PCR results. Relative expression of ALOX15 (a), TNFAIP6 (b), FLG (c), SLURP1 (d) and CRISP3 (e) in paired samples of eosinophilic esophagitis before (BT) and after therapy (AT).

Table 3 Immunohistochemistry results

\begin{tabular}{|c|c|c|c|c|c|c|c|c|c|}
\hline & $\begin{array}{c}\text { Control } \\
\text { positive } \%\end{array}$ & $\begin{array}{c}\text { Eosinophilic } \\
\text { esophagitis } \\
\text { positive \% }\end{array}$ & $\begin{array}{l}\text { Eosinophilic } \\
\text { esophagitis } \\
\text { after treatment } \\
\text { positive \% }\end{array}$ & $\begin{array}{c}\text { Reflux } \\
\text { positive \% }\end{array}$ & $\begin{array}{l}\mathrm{Se} \\
\%\end{array}$ & $\begin{array}{l}S p \\
\%\end{array}$ & $\begin{array}{l}\text { Control vs } \\
\text { eosinophilic } \\
\text { esophagitis } \\
\text { P-value }\end{array}$ & $\begin{array}{c}\text { Eosinophilic } \\
\text { esophagitis } \\
\text { vs reflux } \\
\text { P-value }\end{array}$ & $\begin{array}{c}\text { Eosinophilic } \\
\text { esophagitis } \\
\text { before-vs } \\
\text { after-treatment } \\
\text { P-value }\end{array}$ \\
\hline \multicolumn{10}{|c|}{ Upregulated in eosinophilic esophagitis } \\
\hline ALOX15 & $0(0 / 17)$ & $95(40 / 42)$ & $0(0 / 7)$ & $0(0 / 15)$ & 95 & 100 & $<0.01$ & $<0.01$ & $<0.01$ \\
\hline TNFAIP6 & $47(8 / 17)$ & $88(37 / 42)$ & $29(2 / 7)$ & $40(6 / 15)$ & 88 & 58 & $<0.01$ & $<0.01$ & $<0.01$ \\
\hline \multicolumn{10}{|c|}{ Downregulated in eosinophilic esophagitis } \\
\hline FLG & $88(15 / 17)$ & $0(0 / 42)$ & $86(6 / 7)$ & $100(15 / 15)$ & 100 & 92 & $<0.01$ & $<0.01$ & $<0.01$ \\
\hline SLURP1 & $100(17 / 17)$ & $5(2 / 42)$ & $100(7 / 7)$ & $100(15 / 15)$ & 95 & 96 & $<0.01$ & $<0.01$ & $<0.01$ \\
\hline CRISP3 & $82(14 / 17)$ & $14(6 / 42)$ & $43(3 / 7)$ & $100(15 / 15)$ & 85 & 82 & $<0.01$ & $<0.01$ & 0.10 \\
\hline
\end{tabular}

Abbreviations: Se, sensitivity; Sp, specificity.

\section{Discussion}

In this gene expression study, we used paired samples before and after successful treatment with topical corticosteroids to identify a subset of genes that are differentially expressed by using microarray analysis. Furthermore, we confirmed the microarray results using RT-PCR of paired biopsies before and after treatment and examined their diagnostic utility as potential biomarkers of eosinophilic esophagitis by immunohistochemistry. Screening gene expression alterations by using paired before and after treatment biopsies has advantages over comparing eosinophilic esophagitis with normal controls or reflux samples. First, it decreases the interindividual variations in gene expression levels allowing a more reliable identification of genes differentially expressed because of the disease process. Second, it is known that not all gene expression alterations return to baseline after successful therapy. ${ }^{15}$ By working on those genes that do return to baseline, we create a stage for future research focused on identification of new diagnostic and therapeutic targets. 
ALOX15

a

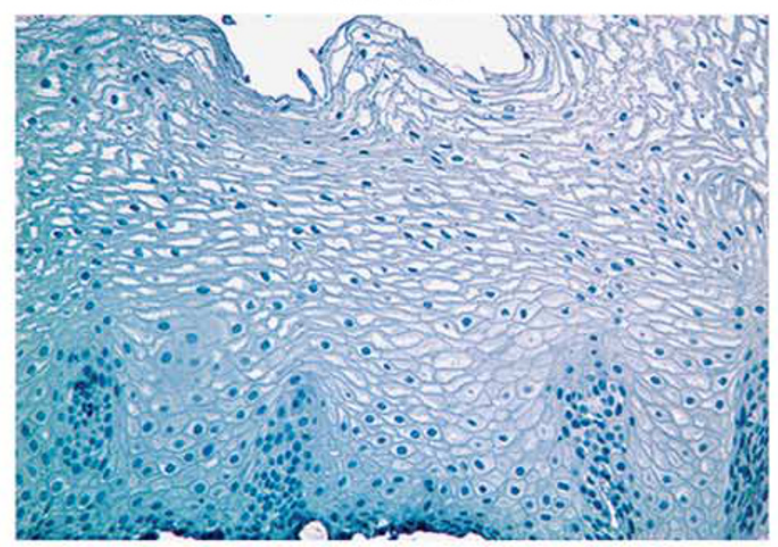

b

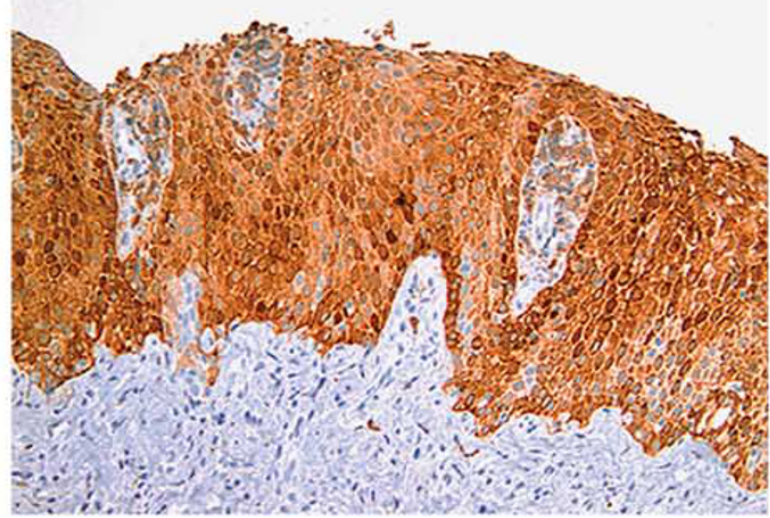

c

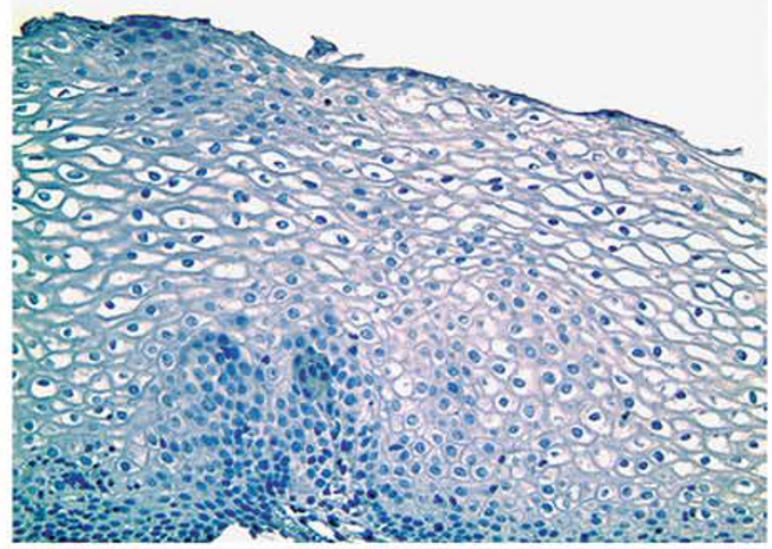

d

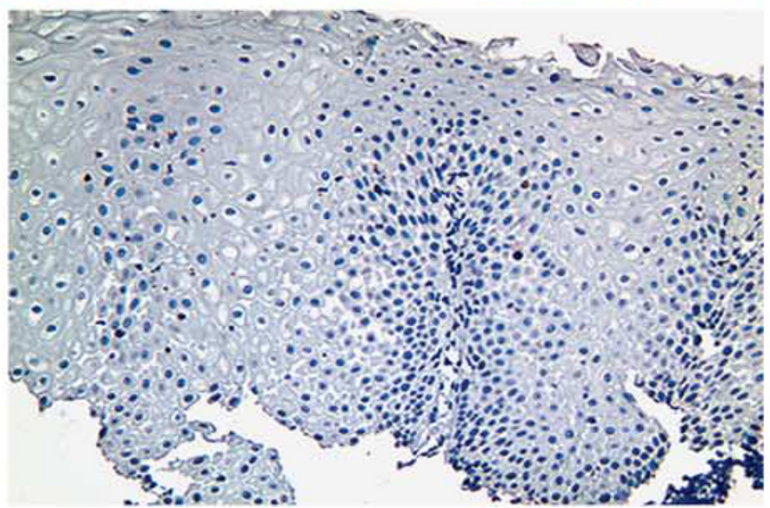

TNFAIP6

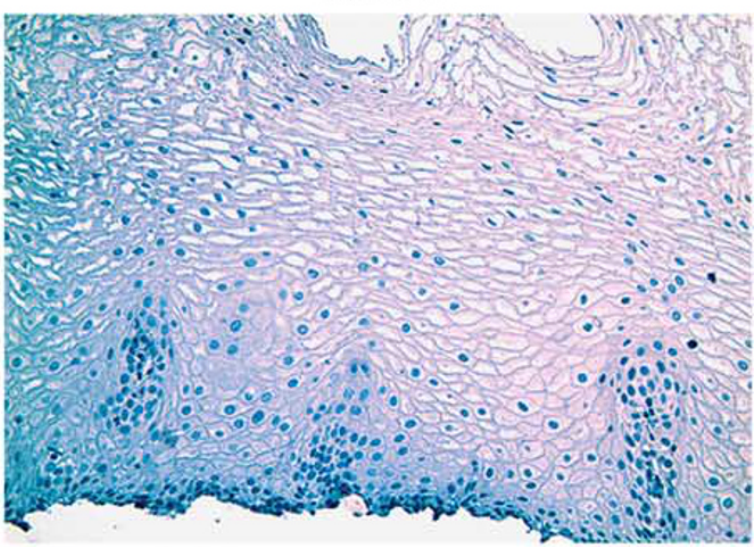

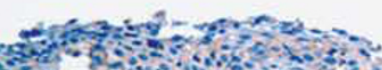
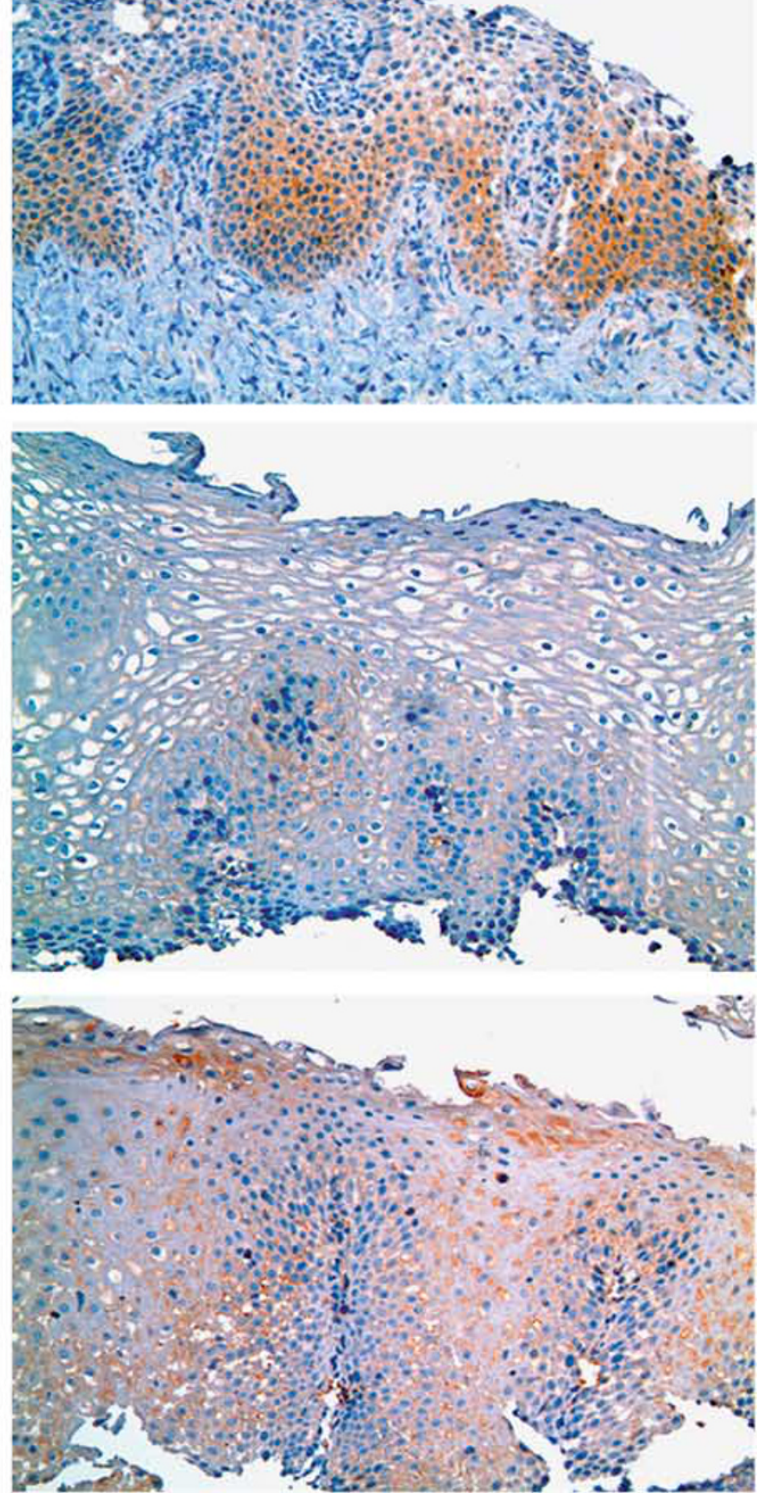
Targets consistently differentially expressed included upregulation of ALOX15 and TNFAIP6 and downregulation of FLG, SLURP1 and CRISP3. As relatively limited data are known concerning the function of these proteins in eosinophilic esophagitis, a summary of the function of each of these genes
FLG

a

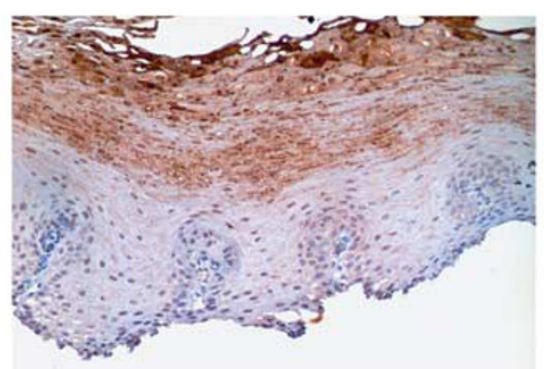

b

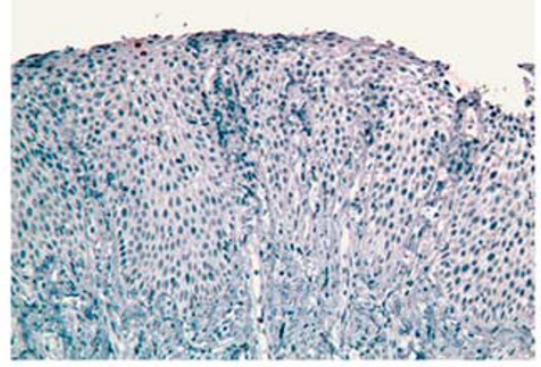

C

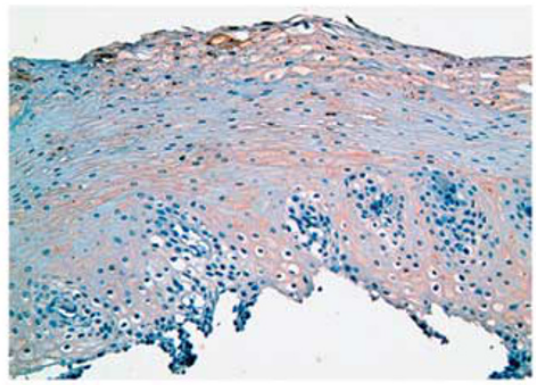

d

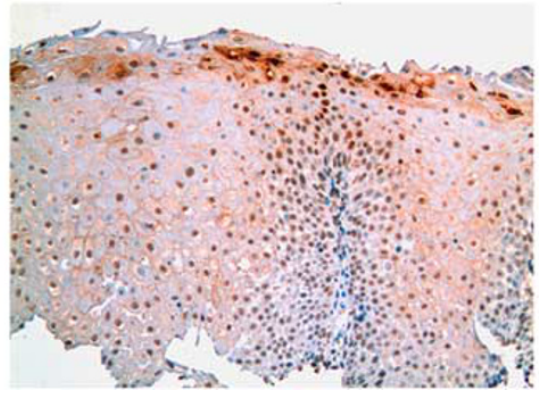

SLURP1
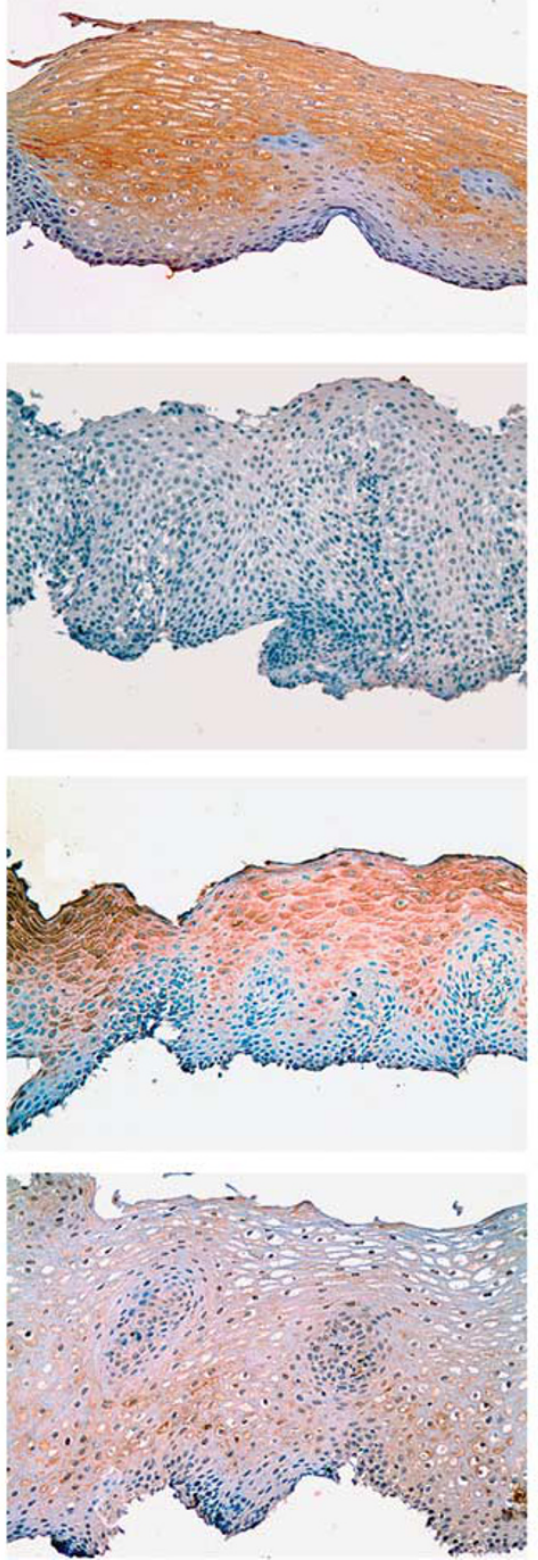

CRISP3
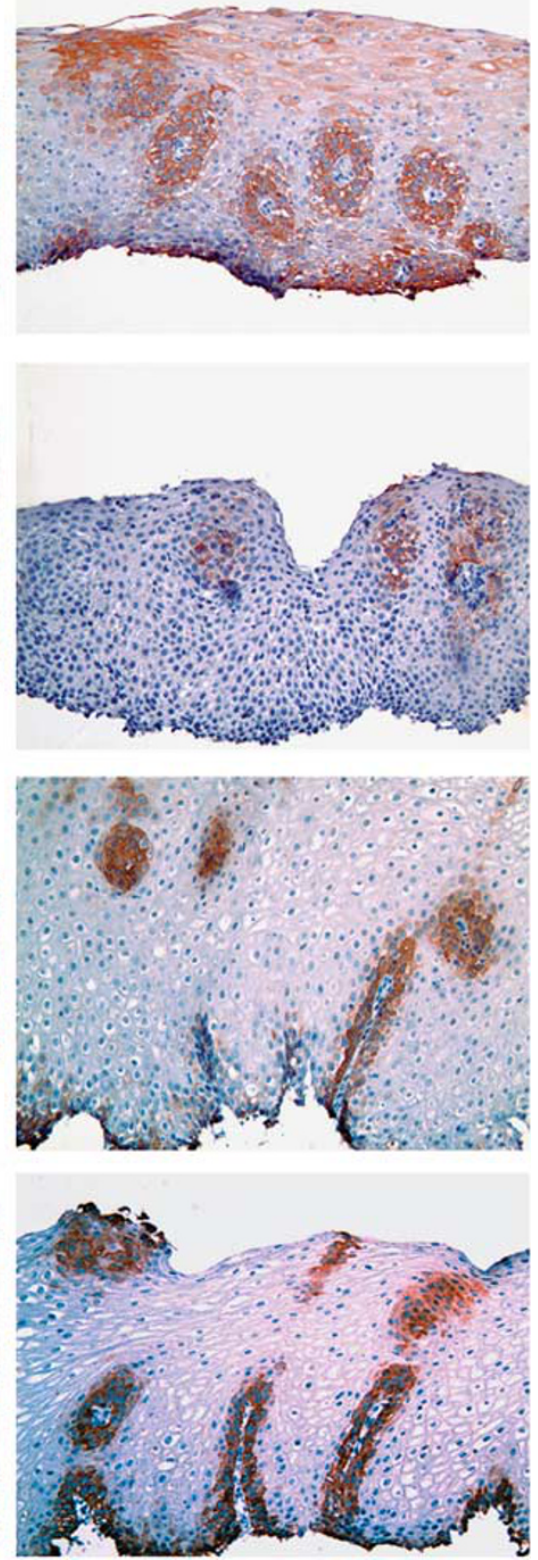

Figure 4 Immunohistochemistry results of FLG, SLURP1 and CRISP3. (a) Normal controls; (b) eosinophilic esophagitis; (c) eosinophilic esophagitis after treatment; (d) reflux. FLG expression was present in the cytoplasm of maturing squamous cells of control samples. Eosinophilic esophagitis biopsies show loss of FLG expression with partial recovery after treatment. Reflux biopsies do not show loss of FLG expression. SLURP1 staining was present in cytoplasm of intermediate and mature squamous epithelial cells of control cases. Expression of SLURP1 is minimal in eosinophilic esophagitis and decreased in reflux cases. CRISP3 expression is strong in the cytoplasm of basal cells and peripapillary cells and in mature superficial squamous cells of control samples. Expression of CRISP3 is decreased in eosinophilic esophagitis. Eosinophilic esophagitis after treatment and reflux cases show CRISP3 expression limited to the basal cells and peripapillary cells but with no expression in cytoplasm of mature squamous cells.

Figure 3 Immunohistochemistry results of ALOX15 and TNFAIP6. (a) Normal controls; (b) eosinophilic esophagitis; (c) eosinophilic esophagitis after treatment; (d) reflux. Normal controls are negative for ALOX15 expression. Expression was strong in cytoplasm of squamous epithelial cells and in inflammatory cells including eosinophils in eosinophilic esophagitis, while it was negative in eosinophilic esophagitis after treatment and reflux biopsies. TNFAIP6 staining was also present in the cytoplasm of squamous epithelial cells in eosinophilic esophagitis patients with marked decrease in expression in eosinophilic esophagitis after treatment samples. Reflux samples showed weak to moderate TNFAIP6 expression. 
a

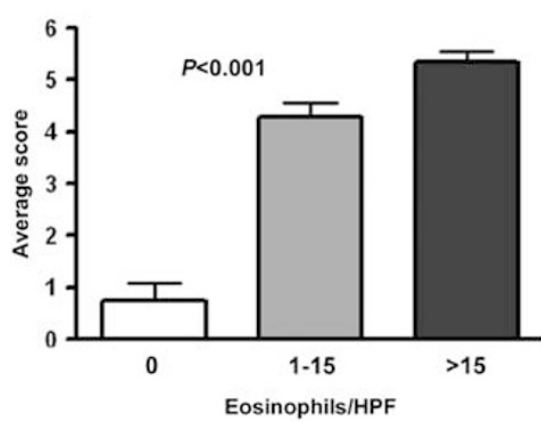

b

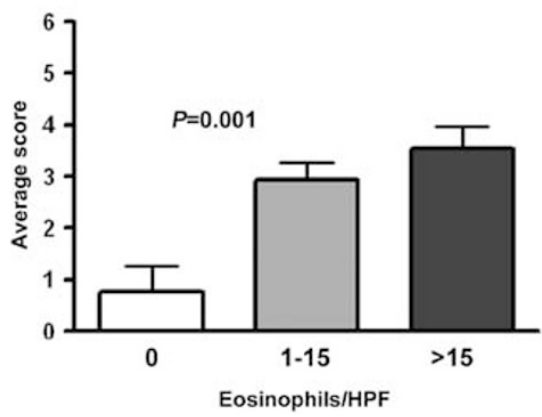

Figure 5 ALOX15 (a) and TNFAIP6 (b) immunohistochemistry stain and degree of eosinophilic infiltration. A combined score of extent and intensity of stain directly correlates with the number of eosinophils per high-power field.

Table 4 Summary of genes differentially expressed in eosinophilic esophagitis

\begin{tabular}{|c|c|c|c|c|}
\hline & Full name & Function & $\begin{array}{l}\text { Constitutive expression in } \\
\text { normal cells }\end{array}$ & Associated diseases \\
\hline$A L O X 15$ & $\begin{array}{l}\text { Arachidonate } \\
\text { 15-lipoxygenase }\end{array}$ & $\begin{array}{l}\text { Oxygenates } \\
\text { polyunsaturated fatty } \\
\text { acids }\end{array}$ & $\begin{array}{l}\text { Eosinophils, macrophages, } \\
\text { endothelial cells and } \\
\text { bronchial epithelium }\end{array}$ & $\begin{array}{l}\text { Upregulated in asthma, }{ }^{16,17} \\
\text { atherosclerosis, }{ }^{18} \text { inflammatory } \\
\text { arthritis. }{ }^{19} \text { Downregulated } \\
\text { in colon polyps and colon cancer. }{ }^{20}\end{array}$ \\
\hline TNFAIP6 & $\begin{array}{l}\text { Tumor necrosis factor, } \\
\text { alpha-induced protein } 6\end{array}$ & $\begin{array}{l}\text { Extracellular matrix } \\
\text { remodeling }\end{array}$ & $\begin{array}{l}\text { Very low expression in } \\
\text { virtually all cell types }\end{array}$ & $\begin{array}{l}\text { Upregulated in systemic lupus } \\
\text { erythematosus, rheumatoid arthritis } \\
\text { and osteoarthritis. }{ }^{21}\end{array}$ \\
\hline$F L G$ & Filaggrin & $\begin{array}{l}\text { Aggregation of keratin } \\
\text { filaments }\end{array}$ & Skin, bronchial epithelium & $\begin{array}{l}\text { Downregulated in atopic dermatitis } \\
\text { and asthma. }\end{array}$ \\
\hline SLURP1 & $\begin{array}{l}\text { Secreted LY6/PLAUR } \\
\text { domain containing } 1\end{array}$ & $\begin{array}{l}\text { Late differentiation of } \\
\text { keratincytes }\end{array}$ & $\begin{array}{l}\text { Skin, vagina, esophagus, } \\
\text { bronchial epithelium }\end{array}$ & $\begin{array}{l}\text { Mutated in Mal de Meleda, } \\
\text { downregulated in asthma. }^{24}\end{array}$ \\
\hline CRISP3 & $\begin{array}{l}\text { Cysteine-rich secretory } \\
\text { protein } 3\end{array}$ & Innate immunity & $\begin{array}{l}\text { Neutrophils, exocrine glands, } \\
\text { epididymis, prostate }\end{array}$ & $\begin{array}{l}\text { Upregulated in prostate cancer and } \\
\text { chronic pancreatitis. }{ }^{25,26}\end{array}$ \\
\hline
\end{tabular}

and their expression in normal tissue and in diseases is presented in Table 4. The upregulation of $A L O X 15$ and TNFAIP6 and downregulation of FLG and CRISP3 was previously noted by microarray analysis comparing eosinophilic esophagitis samples to normal controls. ${ }^{7}$ We confirmed these findings at the protein level and showed that the alteration of expression of these genes was reversible by therapy with topical steroids.

Consistent with the hypothesis that eosinophilic esophagitis is an allergic disorder; ALOX15 was significantly overexpressed in eosinophilic esophagitis biopsies. The ALOX15 pathway has been implicated in asthma pathogenesis and specifically in association with an eosinophilic phenotype and increased fibrosis. ${ }^{16}$ Interestingly, after allergen exposure, Alox15 knockout mice had a markedly decreased number of eosinophils and did not produce specific IgE antibodies. ${ }^{17}$ This suggests that ALOX15 activity is required for the development of sensitization during asthma. Although the significance of increased expression of ALOX15 in patients with eosinophilic esophagitis is currently unknown, it is possible that it has a role in allergen sensitization similar to that in asthma. Notably, epithelial cell ALOX15 expression appears to be very specific for eosinophilic esophagitis. This makes it a potential clinically useful marker for diagnostic purposes as well as a therapeutic target.

TNFAIP6 was first described in the early 1990 s as a cDNA derived from TNF-treated fibroblasts. ${ }^{27}$ TNFAIP6 expression has been associated with inflammation and tissue remodeling. Growth factors including epidermal and fibroblast growth factors upregulate TNFAIP6 synthesis in some cell types. ${ }^{28}$ In this study, we demonstrated overexpression of TNFAIP6 associated with eosinophilic esophagitis. Interestingly, TNFAIP6 has also been shown to have anti-inflammatory activities in different models. For instance, recombinant TNFAIP6 has been shown to improve induced arthritis in mice, ${ }^{29}$ and to reduce inflammatory damage to the cornea following chemical and mechanical injury. ${ }^{30}$

As one of the purposes of this study was to try to identify a diagnostic marker for eosinophilic esophagitis, we further correlated the expression of the two proteins upregulated in eosinophilic esophagitis with the eosinophilic density. Overexpression of both ALOX15 and TNFAIP6 in eosinophilic esophagitis was highest in areas with eosinophilic densities of over 15 per high-power field and was also significant in areas with between 1 and 15 
eosinophils per high-power field. The sensitivity of both ALOX15 and TNFAIP6 expression as markers of eosinophilic esophagitis in areas with no eosinophils per high-power field is low. Given these observations, and the fact that ALOX15 was a more specific marker for eosinophilic esophagitis, the use of ALOX15 may prove useful in identifying patients with eosinophilic esophagitis that because of sampling variations do not meet the current diagnostic criteria of 15 eosinophils per high-power field.

Expression of FLG and SLURP1 were downregulated in eosinophilic esophagitis samples and their expression reconstituted in eosinophilic esophagitis after treatment biopsies. In the skin, FLG aggregates keratin filaments within the cells resulting in the cornified envelope, which is critical for barrier function. Specific loss of function mutations in the FLG gene in patients with atopic dermatitis and in patients with asthma suggests it has a role in the pathogenesis of allergic disorders. ${ }^{22,23}$ Similar to FLG, SLURP1 is associated with intermediate to late differentiation of keratinocytes and is expressed in skin and the mucosa of the gingiva, vagina and esophagus. ${ }^{31}$ In addition to squamous epithelium, expression of SLURP1 has been confirmed in ciliated bronchial epithelial cells and is downregulated in asthma. ${ }^{24}$ The role of SLURP1 and FLG in preservation of the barrier function of esophageal mucosa is not clear at this point, but their downregulation in eosinophilic esophagitis cases is likely to have a role in weakening of the barrier effect of the squamous mucosa with subsequent increase in permeability to pathogens and/or antigens.

Another transcript found to be downregulated in eosinophilic esophagitis is CRISP3. CRISP3 is highly expressed in the male reproductive tract. ${ }^{25}$ Interestingly, a role in innate immune defense has been hypothesized because of its high expression in neutrophils $^{26}$ and exocrine glands. ${ }^{32}$ Whether expression of CRISP3 in esophageal squamous epithelium is somehow related to innate immunity, or involved in the pathogenesis of eosinophilic esophagitis is difficult to establish based on our findings alone.

In summary, our study identifies a subset of markers consistently differentially expressed in eosinophilic esophagitis compared with eosinophilic esophagitis after treatment biopsies, reflux or normal controls. Based on our results, selective overexpression of ALOX15 and loss of expression of FLG and SLURP1 have the highest sensitivity and specificity as diagnostic markers. However, the extent of their diagnostic utility will depend on results of future studies involving adult patients and challenging cases including severe reflux esophagitis with eosinophil counts $>15$ eosinophils per high-power view, patients with disease limited to the lower esophagus, and proton pump inhibitorresponsive esophageal eosinophilia, among others.

\section{Acknowledgements}

Research reported in this publication was supported by the Molecular Pathology Core of the COBRE Center for Cancer Research Development, funded by the National Institute of General Medical Sciences of the National Institutes of Health under Award Number P20GM103421. The previous segment of this project was supported by the National Center for Research Resources (NCRR) under P20RR017695. The content is solely the responsibility of the authors and does not necessarily represent the official views of the National Institutes of Health. This research was also supported by the Rhode Island Hospital Department of Pediatrics Faculty Research Grant to VAM and by the Hearst Foundation Grant to the Hasbro Children Hospital Food Allergy Center.

\section{Disclosure/conflict of interest}

The authors declare no conflict of interest.

\section{References}

1 Kelly KJ, Lazenby AJ, Rowe PC, et al. Eosinophilic esophagitis attributed to gastroesophageal reflux: improvement with an amino acid-based formula. Gastroenterology 1995;109:1503-1512.

2 Noel RJ, Putnam PE, Rothenberg ME. Eosinophilic esophagitis. N Engl J Med 2004;351:940-941.

3 Potter JW, Saeian K, Staff D, et al. Eosinophilic esophagitis in adults: an emerging problem with unique esophageal features. Gastrointest Endosc 2004; 59:355-361.

4 Mueller S, Neureiter D, Aigner T, et al. Comparison of histological parameters for the diagnosis of eosinophilic oesophagitis versus gastro-oesophageal reflux disease on oesophageal biopsy material. Histopathology 2008;53:676-684.

5 Prasad GA, Talley NJ, Romero Y, et al. Prevalence and predictive factors of eosinophilic esophagitis in patients presenting with dysphagia: a prospective study. Am J Gastroenterol 2007;102:2627-2632.

6 Markowitz JE, Spergel JM, Ruchelli E, et al. Elemental diet is an effective treatment for eosinophilic esophagitis in children and adolescents. Am J Gastroenterol 2003;98:777-782.

7 Blanchard C, Wang N, Stringer KF, et al. Eotaxin-3 and a uniquely conserved gene-expression profile in eosinophilic esophagitis. J Clin Invest 2006;116: 536-547.

8 Blanchard C, Mingler MK, Vicario M, et al. IL-13 involvement in eosinophilic esophagitis: transcriptome analysis and reversibility with glucocorticoids. J Allergy Clin Immunol 2007;120:1292-1300.

$9 \mathrm{Lu} \mathrm{S}$, Mukkada VA, Mangray S, et al. MicroRNA profiling in mucosal biopsies of eosinophilic esophagitis patients pre and post treatment with steroids and relationship with mRNA targets. PLoS One 2012;7: e40676. 
10 Mishra A, Hogan SP, Brandt EB, et al. IL-5 promotes eosinophil trafficking to the esophagus. J Immunol 2002;168:2464-2469.

11 Mishra A, Rothenberg ME. Intratracheal IL-13 induces eosinophilic esophagitis by an IL-5, eotaxin-1, and STAT6-dependent mechanism. Gastroenterology 2003;125:1419-1427.

12 Bhattacharya B, Carlsten J, Sabo E, et al. Increased expression of eotaxin-3 distinguishes between eosinophilic esophagitis and gastroesophageal reflux disease. Hum Pathol 2007;38:1744-1753.

13 Liacouras CA, Furuta GT, Hirano I, et al. Eosinophilic esophagitis: updated consensus recommendations for children and adults. J Allergy Clin Immunol 2011;128: 3-20; e26; quiz 21-22.

14 Resnick MB, Sabo E, Meitner PA, et al. Global analysis of the human gastric epithelial transcriptome altered by Helicobacter pylori eradication in vivo. Gut 2006;55:1717-1724.

15 Adcock IM, Ito K, Barnes PJ. Glucocorticoids: effects on gene transcription. Proc Am Thorac Soc 2004;1:247-254.

16 Chu HW, Balzar S, Westcott JY, et al. Expression and activation of 15-lipoxygenase pathway in severe asthma: relationship to eosinophilic phenotype and collagen deposition. Clin Exp Allergy 2002;32:1558-1565.

17 Hajek AR, Lindley AR, Favoreto Jr S, et al. 12/15Lipoxygenase deficiency protects mice from allergic airways inflammation and increases secretory IgA levels. J Allergy Clin Immunol 2008;122:e633.

18 Rong S, Cao Q, Liu M, et al. Macrophage 12/15 lipoxigenase expression increases plasma and hepatic lipid levels and exacerbates atherosclerosis. J Lipid Re 2012;53:686-695.

$19 \mathrm{Wu}$ MY, Lin TH, Chiu YC, et al. Involvement of 15lipoxigenase in the inflammatory arthritis. J Cell Biochem 2012;113:2279-2289.

20 Il Lee S, Zuo X, Shureiqi I. 15-Lipoxigenase-1 as tumor suppressor gene in colon cancer: is the veredict in? Cancer Metastasis Rev 2011;30:491.

21 Milner CN, Day AJ. TSG-6 a multifunctional protein associated with inflammation. J Cell Sci 2003;116: 1863-18673.

22 Morar N, Cookson WO, Harper JI, et al. Filaggrin mutations in children with severe atopic dermatitis. J Invest Dermatol 2007;127:1667-1672.
23 Rodriguez E, Baurecht $\mathrm{H}$, Herberich E, et al. Metaanalysis of filaggrin polymorphisms in eczema and asthma: robust risk factors in atopic disease. J Allergy Clin Immunol 2009;123:e1367.

24 Narumoto O, Horiguchi K, Horiguchi S, et al. Down-regulation of secreted lymphocyte antigen-6/ urokinase-type plasminogen activator receptor-related peptide-1 (SLURP-1), an endogenous allosteric alpha7 nicotinic acetylcholine receptor modulator, in murine and human asthmatic conditions. Biochem Biophys Res Commun 2010;398:713-718.

25 Udby L, Bjartell A, Malm J, et al. Characterization and localization of cysteine-rich secretory protein 3 (CRISP-3) in the human male reproductive tract. J Androl 2005;26:333-342.

26 Udby L, Calafat J, Sorensen OE, et al. Identification of human cysteine-rich secretory protein 3 (CRISP-3) as a matrix protein in a subset of peroxidase-negative granules of neutrophils and in the granules of eosinophils. J Leukoc Biol 2002;72:462-469.

27 Lee $\mathrm{TH}$, Lee GW, Ziff $\mathrm{EB}$, et al. Isolation and characterization of eight tumor necrosis factor-induced gene sequences from human fibroblasts. Mol Cell Biol 1990;10:1982-1988.

28 Feng P, Liau G. Identification of a novel serum and growth factor-inducible gene in vascular smooth muscle cells. J Biol Chem 1993;268:21453.

29 Bardos T, Kamath RV, Mikecz K, et al. Anti-inflammatory and chondroprotective effect of TSG-6 (tumor necrosis factor-alpha-stimulated gene-6) in murine models of experimental arthritis. Am J Pathol 2001; 159:1711-1721.

30 Oh JY, Roddy GW, Choi H, et al. Anti-inflammatory protein TSG-6 reduces inflammatory damage to the cornea following chemical and mechanical injury. Proc Natl Acad Sci USA 2010;107:16875-16880.

31 Mastrangeli R, Donini S, Kelton CA, et al. ARS component B: structural characterization, tissue expression and regulation of the gene and protein (SLURP-1) associated with Mal de Meleda. Eur J Dermatol 2003;13:560-570.

32 Udby L, Cowland JB, Johnsen AH, et al. An ELISA for SGP28/CRISP-3, a cysteine-rich secretory protein in human neutrophils, plasma, and exocrine secretions. J Immunol Methods 2002;263:43-55. 